\title{
What is the function of the cone-rich rim of the retina?
}

\begin{abstract}
Although there is good histological evidence for a rim of cones extending round the margin of the human retina at the ora serrata, the function of these cones is unknown, and indeed it is not known whether they are functional at all. Four possibilities are discussed here: (i) the cones of the ora serrata may alert us to sudden movements in the far peripheral field, (ii) their signal may be used in estimating optic flow during locomotion, (iii) they may integrate light scattered within the globe of the eye or passing through the sclera, for purposes of colour constancy, or (iv) they may drive circadian rhythms. We report two experiments designed to detect psychophysical correlates of the cone rim. Under the conditions we have used, neither flicker detection nor colour naming show, near the limit of vision, a discontinuity that would correspond to the cone-rich rim.
\end{abstract}

Key words Colour constancy, Cone, Cone streak, Flicker, Optic flow, Ora serrata, Peripheral retina

In his authoritative monograph of 1941, Polyak devotes only a single sentence to the extreme periphery of the retina, dismissing it as of 'small physiological interest. ${ }^{1}$ Yet the histology of the retinal margin gives reason to question Polyak's view. At the very edge of the retina, adjacent to the ora serrata, is a $1 \mathrm{~mm}$ wide rim where cones predominate rather than rods. Schultze ${ }^{2}$

B.C. Regan

Department of Experimental

Psychology

University of Cambridge

Downing Street

Cambridge CB2 3EB, UK

J.K. Bowmaker

Department of Visual

Science

Institute of Ophthalmology University College London

Bath Street

London EC1V 9EL, UK

This paper is dedicated to the memory of Professor H.J.A. Dartnall (1913-1998)

Supported by MRC grant 9712483
J.D. MOLLON, B.C. REGAN,

J.K. BOWMAKER cones in comparison to the 75000 of the fovea. Up to $90 \%$ of the inner segments in this region can be labelled by an antibody against the long-/middle-wave cone opsins, while a small minority of inner segments are labelled by an antibody against the short-wave cone opsin.

Does the cone rim have a function and what might that function be? These questions are linked to a third unanswered question: Do rays from the external world directly reach the ora serrata? The limit of vision in the temporal field certainly lies beyond the limit of a standard perimeter. Hartridge ${ }^{5}$ in 1919 measured it directly as $104^{\circ}$, and that would agree with our own values: Fig. $1 \mathrm{~b}$ shows his interpretation of the ray path. Two other measurements are relevant: Druault ${ }^{6}$ in 1898 found that bright lights placed at just over $100^{\circ}$ produced, in a darkened room, an image visible through the contralateral sclera of blue-eyed patients; and Jay, ${ }^{7}$ illuminating the fundus along a temporal line of sight, found that the effective area of the laterally observed pupil fell to zero at around $107^{\circ}$.

However, there seems to be no firm evidence as to whether the limit of vision in the temporal field corresponds to the ora serrata or to a point posterior to the margin of the retina. Donders ${ }^{8}$ believed the last millimetre of the retina was non-functional, and this tradition was carried on by Duke-Elder, ${ }^{9}$ who spoke of a pars caeca at the retinal margin, and by Thiel. ${ }^{10}$ Donders' argument - interesting in retrospect - was that visual purple was absent from the final millimetre. Thiel argued from the fact that the terminal retina appeared very thin and lacked ganglion cells, their place being taken by Müller fibres. Characteristic of this part of the retina are peculiar cavities ('Blessig's cysts'), which have often been taken to indicate the degenerate nature of the region. Salzmann ${ }^{11}$ states that they appear 'as rounded pores, or, through confluence of adjoining cavities, as lobulated or meandering or dendritically branched clear flecks'. The cysts appear early in life, 'between perhaps the years of 16 and $20^{\prime}$ according to Salzmann, and with age they increase in size and extent. ${ }^{11}$ Moreover, the cones of this region are often described as 'destroyed', ${ }^{12}$ 'partially destroyed ${ }^{13}$ or 'malformed', with 'poorly developed outer segments'. ${ }^{14}$ 


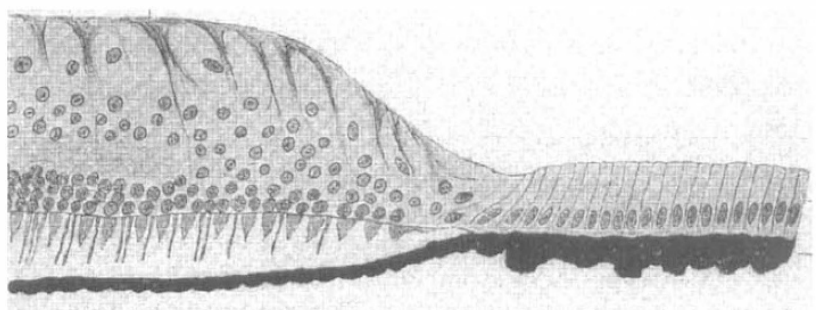

(a)

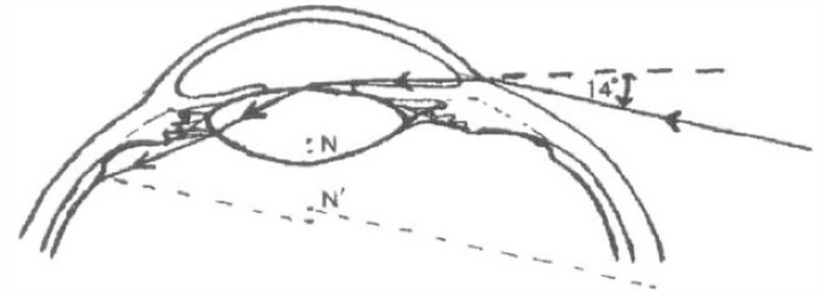

(b)

Fig. 1. (a) Vertical section through the junction of the retina (left) and orbiculus ciliaris (right) in the region of the ora serrata (from Greeff 1900). Notice that rods become fezver and cones more frequent as the edge of the retina is approached. (b) Hartridge's (1919) representation of the probable ray path for a stimulus at the limit of the visual field.

On the other hand, in the preparations of Williams ${ }^{4}$ the cones are mostly well formed and well ordered, and ganglion cells are present. We have ourselves measured microspectrophotometrically a small sample of cones from the region of the ora serrata in macaque and marmoset retinas and have found that they contain measurable levels of photopigment. One further observation favours the view that the cone-rich rim is functional: Williams ${ }^{4}$ found the cone rim is most pronounced on the nasal and upper nasal edges of the retina (see also Diaz-Araya et al. ${ }^{15}$ ); this asymmetry is to be expected if the purpose of the rim is to detect stimuli in the extreme lateral field, since the edge of the retina is elsewhere shielded by the nose, the eyebrow and the cheek. The cross-over point at which the retinal surface is covered equally by rods and cones lies $1.5 \mathrm{~mm}$ from the edge in the nasal sector and about $1 \mathrm{~mm}$ elsewhere, and the cone:rod ratio remains relatively high at greater distances from the edge on the nasal side; indeed, the cone-rich nasal rim could be seen as the terminus of a 'cone streak'12,15 that runs along the nasal horizontal meridian. Salzmann" noted that the teeth of the ora serrata are most marked on the nasal side, whereas 'on the temporal side they often fail completely, and the border is then only finely and irregularly wavy or angular.'

If the cone-rich rim is in fact functional, then at least four possible functions might be suggested:

1. Alerting. A classical view is that the extreme periphery serves as a sentinel, being specialised for detecting the sudden movements or sudden changes of illumination that indicate biologically important stimuli: its role is to alert us to predators and other threats behind us, and to trigger foveation. Historically, these functions were often attributed to peripheral rods and so sat uncomfortably with perceptual indications that the scotopic response was slow (consider, for example, the discussion in Parsons' textbook ${ }^{16}$ ). Cones have intrinsically shorter time constants than rods, ${ }^{17,18}$ owing perhaps to the different kinetics of their secondmessenger system or to differences in the control of cytoplasmic calcium concentration. ${ }^{18}$ Cones are thus better suited than rods to detecting rapid modulation and to triggering a more rapid response.*

2. Measurement of optic flow. During locomotion, we judge our own movement, and our relationship to surrounding objects, by the rate of flow of texture elements across the peripheral field. ${ }^{19,20}$ These judgements are largely unconscious. If we are moving forwards and are looking straight ahead, then the rate of optic flow is maximal at $90^{\circ}$, i.e. in a part of the field corresponding to the most anterior retina. The rate of optic flow is proportional to our own speed of travel and inversely proportional to the distance from us of surrounding objects. If we fixate a point other than one on the midline towards which we are travelling, then an inequality will be introduced between the rates of flow in the left and right temporal fields. Since the rates of optic flow near $90^{\circ}$ can be high, cones would seem much more suitable than rods for extracting such rates of flow, owing to the intrinsically faster kinetics of the cone response. This second hypothesis would particularly favour a view in which the nasal rim is functionally part of a larger cone streak running along the horizontal nasal meridian and subserving the analysis of optic flow.

3. Colour constancy. Perhaps the cone rim has evolved to be illuminated primarily by scattered light within the globe of the eye. Even if external rays do reach the ora serrata directly, the ratio of scattered light to direct light must be highest in this region of the retina, since the effective area of the pupil is reduced to 0.1 at $98^{\circ}$ and 0.05 at $100^{\circ} .7$ If the cone rim measures the integrated scattered light of the eye, it could provide a measure of the chromaticity of the illuminant and so subserve colour constancy. To achieve colour constancy, to recover the spectral reflectances of local surfaces, we need to estimate the colour of the illuminant. Some observations reported in 1900 by Hellpach ${ }^{21}$ might be invoked in support of the hypothesis that the cone rim contributes to colour constancy. At the time, these results were

${ }^{*}$ Curcio and colleagues ${ }^{12}$ have identified additional patches of cone-rich retina adjacent to the optic disc (see their figure 4). These cones have large inner segments $(10 \mu \mathrm{m})$ and are polygonal in shape, in a way that reflects their packing. Ganglion cells drawing input from such cone patches would have the very fastest access to cortical and sub-cortical response systems, since their axons must enter the optic nerve almost directly. The cone patches of the disc are therefore alternative or additional candidates for the function that we are postulating in this section. This hypothesis would also predict a specialisation of post-receptoral cells in the region of the disc, with perhaps few midget ganglion cells and an abundance of parasol ganglion cells or of rare types of ganglion cell with projections to the superior colliculus. 
attributed to adaptation from earlier presentations of the stimulus, ${ }^{22,23}$ and they have been little discussed since. Hellpach studied colour vision in the far periphery under dark-adapted conditions where the pupil might be expected to be large. He reported, as had others, a peripheral zone where coloured lights appeared colourless, but at more extreme eccentricities he claimed a gegenfarbige Zone, where the colours were paradoxical: red, orange and yellow evoked a bluish sensation whereas blue and violet evoked a yellowish sensation. This paradoxical response is what one might expect if Hellpach were managing to stimulate receptors whose normal job was to identify the spectral bias of the illuminant and whose signal was used to compensate for this bias. Another variant of this hypothesis might hold that the cone rim responds to light passing through the sclera: this Augenhüllenlicht is the reference signal in the theory of colour constancy proposed in 1931 by Pikler, ${ }^{24}$ who claimed to vary the appearance of a surface by manipulating the intensity and spectral composition of light falling on the sclera. An obvious difficulty for such theories of colour constancy would arise if corrections appropriate to different illuminants could be made concurrently in distinct areas of the retina; but in fact the work of Arend and Reeves ${ }^{25}$ suggests that colour constancy is imperfect when two differently illuminated domains are simultaneously present, and when the observer is asked to judge the phenomenological hue of a target patch.

4. Circadian rhythms. This last hypothesis would also assume that the cone rim is primarily stimulated by light integrated within the globe or passing through the sclera. The resulting signal might be used as a Zeitgeber to drive circadian rhythms. If the rim contains cones of different types, there is the possibility that it is the chromaticity as much as the level of light that is measured: at dawn and dusk there are rather rapid changes in the spectral composition of daylight ${ }^{26}$ and these might give a more exact time marker than would overall light intensity. ${ }^{27}$ On this hypothesis, we should not necessarily expect the cones at the ora serrata to contain the standard cone pigments.

In current research, we hope to elucidate the function of the cone-rich rim by parallel psychophysical and microspectrophotometric investigations. We report here two psychophysical experiments designed to search for a perceptual discontinuity at the margin of vision that would correspond to the sudden change in rod:cone ratio described histologically.

\section{Experiment 1: Modulation sensitivity}

In this experiment we set out psychophysically to isolate a cone response to flicker. Some of the traditional means of separating rods and cones were not open to us: bleaching would be difficult, since the reduced aperture of the pupil would attenuate the bleaching light; and there is no scope for varying the point of pupil entry in order to exploit the greater directional selectivity of cones - the Stiles-Crawford effect. ${ }^{28}$ We therefore adopted a method of silent substitution.

The stimulus was a vertical bar, subtending $8.6^{\circ} \times 1^{\circ}$ and presented on a computer-controlled colour graphics monitor (Sony GDM-1936), which was placed in the temporal field of the subject's left eye. The background was dim. In its steady state, the stimulus bar appeared white, but it was composed of blue and yellow components that were of equal scotopic luminance (Fig. 2). Flicker visible to the cones was produced by modulating the blue and yellow components in counterphase at $18 \mathrm{~Hz}$; the dependent variable in the experiment was the depth of modulation. The modulation was Gaussian-filtered in time, to attenuate low-frequency components that might be salient for rods. The photopic luminance of the stimulus bar in the steady state was $35 \mathrm{~cd} / \mathrm{m}^{2}$; the maximum available photopic luminance (corresponding to the yellow component alone) was $60 \mathrm{~cd} / \mathrm{m}^{2}$ and the minimum (corresponding to the blue component) was $10 \mathrm{~cd} / \mathrm{m}^{2}$.

We do not claim the silent substitution was exact for the rods: we used the standard scotopic sensitivity curve $\left(V^{\prime} \lambda\right)$ for our calibration and it is not known how exactly this curve describes the spectral sensitivity of the far periphery, where, for example, the path through the lens is different from that for a parafoveal ray and where chromatic aberration may selectively attenuate some spectral components of the stimulus. We claim only that the flicker would be much more visible to cones than to rods. The flicker rate would additionally favour cones.

Thresholds for detecting modulation were measured by a two-alternative forced-choice procedure: on any trial, the bar remained steady on one presentation and on
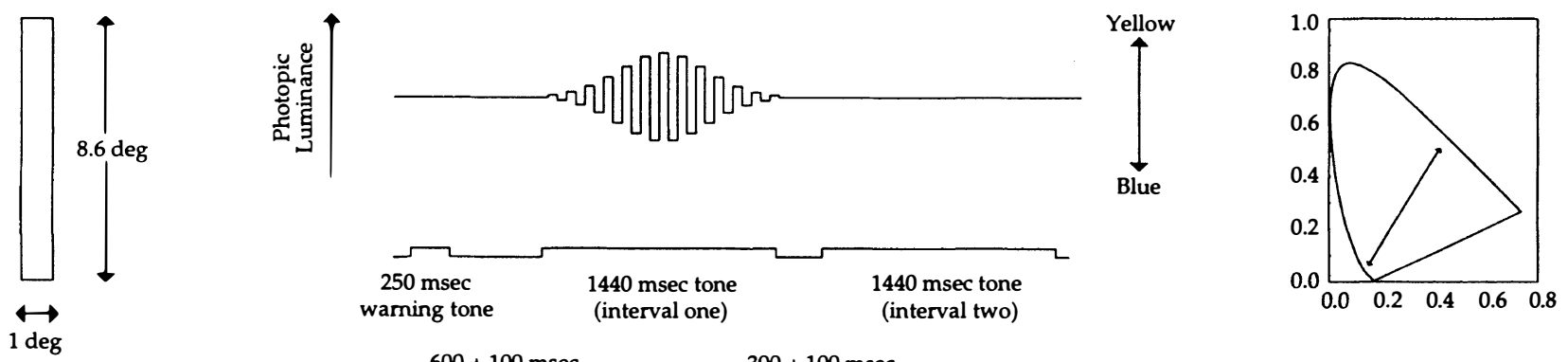

$600 \pm 100 \mathrm{msec}$

$300 \pm 100 \mathrm{msec}$

Fig. 2. Representation of the stimulus used in experiment 1, showing its spatial (left), temporal (centre) and chromatic (right) features. The modulation of photopic luminance is achieved by counterphase modulation of blue and yellow components of equal scotopic luminance. Different depths of modulation correspond to excursions of different length in the CIE (1931) chromaticity diagram shown to the right. 

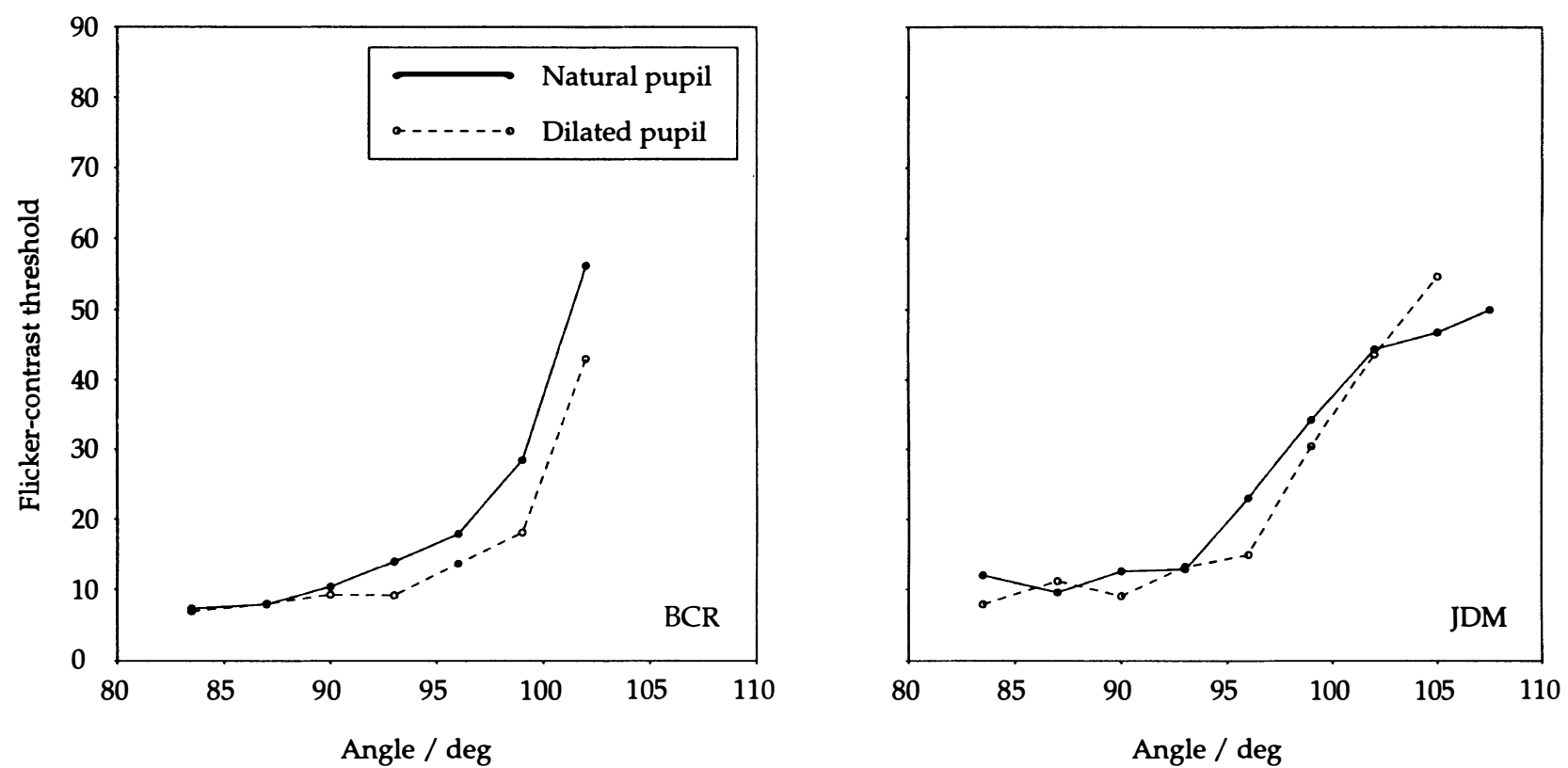

Fig. 3. Results for experiment 1, showing the percentage luminance modulation at threshold as a function of visual angle. Left and right panels represent results for subjects B.C.R. and J.D.M. respectively.

the other, its photopic luminance was modulated. Each presentation lasted $1440 \mathrm{~ms}$ and was indicated by a concurrent tone (Fig. 2). The subject indicated by pushbuttons the interval containing the modulation. The computer program incorporated a staircase procedure, adjusting the depth of modulation according to the accuracy of the subject's response. Within each experimental run, ten eccentricities between $83^{\circ}$ and $110^{\circ}$ were probed in random order. The room was dark except for a central screened area, where the alternative fixation points were illuminated by white light $\left(23 \mathrm{~cd} / \mathrm{m}^{2}\right)$. The right eye was covered.

The subjects were two of the authors (J.D.M., B.C.R.), both male and both myopic. In the light of reports that Blessig's cysts become more marked throughout adult life, ${ }^{11}$ we note that J.D.M. is aged 53 years and B.C.R., 26. On the basis of clinical reports that the ora serrata can be seen ophthalmoscopically only in the dilated eye, we ran the experiment both with the natural pupil and after dilation with a mydriatic. These conditions were counterbalanced in a series of eight runs.

The results of experiment 1 are shown in Fig. 3, where the ordinate represents the depth of modulation at threshold and the abscissa represents eccentricity. Both for the natural pupil and for the dilated pupil, thresholds rise monotonically at the margin of vision: there is no evidence for a region of enhanced flicker sensitivity, such as might indicate the presence of the cone-rich rim. Dilation of the pupil has surprisingly little effect: for B.C.R. the lateral shift of the function is at most $3^{\circ}$, and for J.D.M. it is less.

\section{Experiment 2: Colour naming}

In this experiment we searched at the edge of the temporal field for either a region of enhanced colour discrimination or the gegenfarbige Zone that Hellpach had claimed in 1900 to find at extreme eccentricities. On each trial a single green or magenta bar was presented on the graphics monitor used in experiment 1 . The spatial dimensions of the bar were as in Fig. 2 and its CIE (1931) $x, y$ chromaticity coordinates were either $0.28,0.61$ or $0.39,0.21$. The subject was asked to indicate the colour of the bar by means of pushbuttons. To prevent his being influenced by luminance cues, we took two precautions: (i) the green and magenta bars were equated in both average scotopic and average photopic luminance and (ii) a random variation in luminance was introduced from trial to trial. The photopic luminances ranged from 5 to $20 \mathrm{~cd} / \mathrm{m}^{2}$ in steps of 5 . In this experiment, unlike the previous one, the instruction to the subject was to give

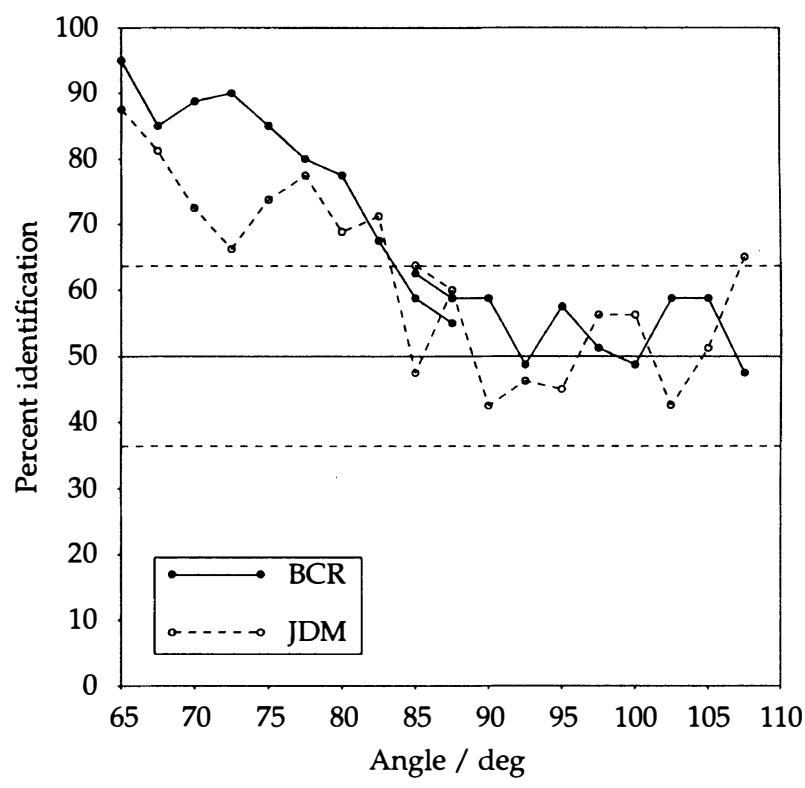

Fig. 4. Results for experiment 2, showing the percentage of trials on which colours were correctly identified at different eccentricities. The horizontal broken lines represent the 95\% confidence limits for chance performance. 
the response that more nearly corresponded to the colour perceived rather than to achieve correct performance.

The stimulus was presented in the temporal field of the left eye. The right eye was covered and the natural pupil was used. Except during stimulus presentations, the entire field was dark and fixation was guided by a small illuminated spot. A warning tone occurred $600 \mathrm{~ms}$ before the onset of the stimulus and the duration of the stimulus was $1440 \mathrm{~ms}$. An experimental sequence of 40 presentations was devoted to a given eccentricity. Different eccentricities were tested in random order. Since we wished to examine a range of eccentricities, two overlapping types of run were made: one from $65^{\circ}$ to $87.5^{\circ}$ and the other from $85^{\circ}$ to $107.5^{\circ}$. The two types of run were performed in counterbalanced order.

Results for the two subjects are shown in Fig. 4. The proportion of correct identifications of the colour of the test bar declines monotonically as eccentricity increases above $65^{\circ}$ and reaches chance levels around $85^{\circ}$. There is no indication either of a region of enhanced colour discrimination at the edge of the field or of a gegenfarbige Zone where responses are below chance. In the region of chance identifications, subjects reported complex percepts of desaturated hues rather than purely achromatic sensations.

\section{Conclusions}

We have described two experiments in which we have searched for a psychophysical correlate of the cone-rich rim of the human retina. Under the conditions used here, neither detection of modulation nor colour naming exhibits, near the margin of vision, a discontinuity that might correspond to the discontinuity seen histologically. It remains possible that a discontinuity might be detected in younger subjects, or by a different measure (e.g. the threshold for reporting direction of movement). It is possible too that the cone rim, though functional, is normally not stimulated by direct rays but by light scattered within the globe of the eye.

If, as Hartridge ${ }^{5}$ supposed, the limit to vision is set by refraction at the corneal surface, a complication that must be considered in future studies is chromatic aberration. At the moment of the setting of the sun, as its upper limb falls below an ocean horizon, one may see a green flash. ${ }^{29}$ The classical explanation of this physical phenomenon is that the medium- and short-wave rays from the sun are still being refracted to the observer by the earth's atmosphere at a moment when the less refrangible longwave rays are passing over the observer's head. By analogy, as we move a broad-band source outwards past the margin of an observer's temporal field, we might expect the limit of vision to be greater for short wavelengths and the edge of the retina to exhibit a distorted spectral sensitivity.

We are grateful to Petroc Sumner and Matthew Simunovíc for discussion and assistance.

\section{References}

1. Polyak SL. The retina. Chicago: University of Chicago Press, 1941.

2. Schultze M. Zur Anatomie und Physiologie der Retina. Arch Mikrosc Anat 1866;2:174-286.

3. Greeff R. Mikroscopische Anatomie der Sehnerven und der Netzhaut. In: von Graefe A, Saemisch T, editors. Handbuch der gesamten Augenheilkunde. Berlin: Springer, 1900.

4. Williams RW. The human retina has a cone-enriched rim. Vis Neurosci 1991;6:403-6.

5. Hartridge H. The limit to peripheral vision. J Physiol (Lond) 1919;53:17.

6. Druault A. Note sur la situation des images rétiniènnes formées par les rayons très obliques sur l'axe optique. Arch d'Ophtalmol 1898;20:685-92.

7. Jay BS. Pupil area at different eccentricities. Vision Res 1961;1:418-24.

8. Donders FC. Die Grenzen des Gesichtsfeldes in Beziehung zu denen der Netzhaut. Graefes Arch Ophthalmol 1877;2:255-80.

9. Duke-Elder WS. Textbook of ophthalmology, vol I. London: Kimpton, 1932.

10. Thiel H-L. Zur topographischen und histologischen Situation der Ora serrata. Graefes Arch Ophthalmol 1955;156:590-629.

11. Salzmann M. The anatomy and histology of the human eyeball in the normal state. Chicago: University of Chicago Press, 1912.

12. Curcio CA, Sloan KR, Kalina RE, Hendrickson AE. Human photoreceptor topography. J Comp Neurol 1990;292:497-523.

13. Joussen F, Spitznas M. The fine structure of the human retina at the ora serrata. Graefes Arch Ophthalmol 1972;185:177-88.

14. Fine BS, Yanoff M. Ocular histology. New York: Harper \& Row, 1972.

15. Diaz-Araya CM, Provis JM, Billson FA. NADPH-diaphorase histochemistry reveals cone distributions in adult human retina. Aust NZ J Ophthalmol 1993;2:171-9.

16. Parsons JH. An introduction to the theory of perception. Cambridge: Cambridge University Press, 1927.

17. Schnapf J, Nunn BJ, Meister M, Baylor DA. Visual transduction in cones of the monkey Macaca fascicularis. J Physiol (Lond) 1990;427:681-713.

18. Miller JL, Picones AP, Korenbrot JI. Differences in transduction between rod and cone photoreceptors: an exploration of the role of calcium homeostasis. Curr Opin Neurobiol 1994;4:488-95.

19. Helmholtz H. Handbuch der physiologischen Optik. 1 ed. Leipzig: Leopold Voss, 1867.

20. Gibson JJ. The perception of the visual world. Boston: Houghton Mifflin, 1950.

21. Hellpach W. Die Farbenwahrnehmung im indirecten Sehen. Philosophische Studien 1900;15:524-54.

22. Baird JW. The color sensitivity of the peripheral retina. Washington: Carnegie Institute, 1905.

23. Baird JW. Review of: Die Farbenempfindung der Netzhautperipherie bei Dunkeladaptation und konstanter subjectiver Helligkeit, by Wilhelm Peters. J Philos Psychol Sci Methods 1905;2:20-2.

24. Pikler J. Das Augenhüllenlicht als Mass der Farben. Z Psychol 1931;120:189-208.

25. Arend L, Reeves A. Simultaneous color constancy. J Opt Soc Am A 1986;3:1743-51.

26. Munz FW, McFarland WF. Evolutionary adaptation of fishes to the photic environment. In: Crescitelli F, editor. Handbook of sensory physiology. Berlin: Springer, 1977.

27. Mollon JD, Jordan G. Eine evolutionäre Interpretation des menschlichen Farbensehens. Die Farbe 1988;35/36:139-70.

28. Stiles WS. The directional sensitivity of the retina and the spectral sensitivities of the rods and cones. Proc R Soc Lond B 1939;127:64-105.

29. O'Connell DJK. The green flash. Sci Am 1960;202:112. 